\title{
UJI KINERJA TAHAP AWAL SISTEM PROMPT GAMMA NEUTRON ACTIVATION ANALYSIS (PGNAA) MENGGUNAKAN SUMBER NEUTRON PUBe UNTUK UJI KUALITAS SEMEN
}

\section{PRELIMINARY PERFORMANCE TEST OF PROMPT GAMMA NEUTRON ACTIVATION ANALYSIS (PGNAA) SYSTEM USING PUBE NEUTRON SOURCE FOR TEST QUALITY OF CEMENT}

Fahma Roswita 1 , Syarip ${ }^{2}$, Anung Muharini ${ }^{3}$

1,3 Departemen Teknik Nuklir dan Teknik Fisika - Universitas Gadjah Mada, Jln. Grafika 2 Yogyakarta 55281

2 Pusat Studi Teknologi Akselerator (PSTA) - BATAN, Jalan Babarsari, Kotak Pos 6101 YKBB Yogyakarta email: fahmaroswita@gmail.com

Diterima 21 November 2017, diterima dalam bentuk perbaikan 25 Juli 2019, disetujui 22 Agustus 2019

\begin{abstract}
ABSTRAK
UJI KINERJA TAHAP AWAL SISTEM PROMPT GAMMA NEUTRON ACTIVATION ANALYSIS (PGNAA) MENGGUNAKAN SUMBER NEUTRON PuBe UNTUK UJI KUALITAS SEMEN. Telah dilakukan perancangan dan uji kinerja sistem Prompt Gamma Neutron Activation Analysis (PGNAA) dengan sumber neutron isotopik PuBe untuk pengujian bulk sample. Metodologi yang digunakan adalah pengukuran fluks neutron dengan metode aktivasi untuk dapat melakukan perancangan container sumber neutron dan penyusunan sistem Prompt Gamma Neutron Activation Analysis (PGNAA). Hasil pengukuran fluks neutron termal dari sumber neutron PuBe pada jarak $5 \mathrm{~cm}, 10 \mathrm{~cm}, 15 \mathrm{~cm}$, dan $20 \mathrm{~cm}$ di dalam media air berturut-turut adalah $1,3676 \times 10^{4} \mathrm{ncm}^{-2} \mathrm{~s}^{-1} ; 6,832 \times 10^{3} \mathrm{n} \mathrm{cm}^{-2} \mathrm{~s}^{-1} ; 1,922 \times 10^{3} \mathrm{n} \mathrm{cm}^{-2} \mathrm{~s}^{-1}$ dan $1,4678 \times 10^{3} \mathrm{n} \mathrm{cm}^{-2} \mathrm{~s}^{-1}$. Sistem PGNAA yang dirancang berbasis detektor gamma NalTI dengan sumber neutron isotopik PuBe. Hasil uji kinerja menunjukkan bahwa sistem PGNAA tesebut dapat mengaktivasi sampel semen dengan cukup baik. Hasil uji coba menggunakan sampel semen curah (bulk sample) terdeteksi 4 puncak energi gamma. Terdapat 2 puncak gamma yang diindikasi sebagai unsur mayor pada sampel semen yaitu unsur ${ }^{59} \mathrm{Fe}$ dan ${ }^{28} \mathrm{Al}$. Puncak energi gamma yang ketiga diindikasi terdapat 2 unsur minor sampel semen yaitu ${ }^{63} \mathrm{Zn}$ dan ${ }^{25} \mathrm{Na}$, dan puncak energi gamma yang keempat diindikasi sebagai unsur minor pada sampel semen yaitu ${ }^{56} \mathrm{Mn}$.
\end{abstract}

Kata kunci: PGNAA, neutron, gamma, PuBe, iradiasi, fluks neutron

\begin{abstract}
PRELIMINARY PERFORMANCE TEST OF PROMPT GAMMA NEUTRON ACTIVATION ANALYSIS (PGNAA) SYSTEM USING PUBE NEUTRON SOURCE FOR TEST QUALITY OF CEMENT. The arrangement of Prompt Gamma Neutron Activation Analysis (PGNAA) with PuBe isotopic neutron source for bulk sample testing has been done. The methodology used is a calculation of neutron flux with activation method for designing neutron source container and arrangement Prompt Gamma Neutron Activation Analysis (PGNAA) system. The total neutron flux values measured from the PuBe neutron source at a distance of 5 $\mathrm{cm}, 10 \mathrm{~cm}, 15 \mathrm{~cm}$, and $20 \mathrm{~cm}$ underwater were $1,3676 \times 10^{4} \mathrm{n} \mathrm{cm}^{-2} \mathrm{~s}^{-1} ; 6,832 \times 10^{3} \mathrm{n} \mathrm{cm}^{-2} \mathrm{~s}^{-1} ; 1,922 \times 10^{3} \mathrm{n} \mathrm{cm}$. ${ }^{2} \mathrm{~s}^{-1}$ and $1,4678 \times 10^{3} \mathrm{n} \mathrm{cm}^{-2} \mathrm{~s}^{-1}$ respectively. The PGNAA system is designed using NalTI gamma detector and PuBe neutron source. The performance test showed that the PGNAA system can activate cement sample well enough. The test using cement samples resulted in 4 peaks of gamma energy. The first two (2) peaks indicated as major elements in the cement sample, i.e. ${ }^{59} \mathrm{Fe}$ and ${ }^{28} \mathrm{Al}$. The third peak of gamma energy

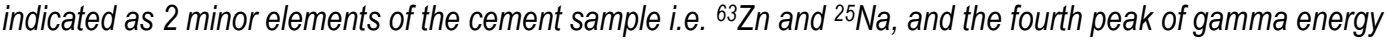
indicated as ${ }^{56} \mathrm{Mn}$, a minor element in the cement sample.
\end{abstract}

Keywords: PGNAA, neutron, gamma, PuBe, irradiation, neutron flux

\section{PENDAHULUAN}

Analisis aktivasi neutron (AAN) pertama kali ditemukan oleh Hilde Levi dan George de Hevesy pada tahun 1936 di Copenhagen dengan menggunakan sumber neutron RaBe (radium-berilium) untuk aktivasi unsur tanah jarang. Pada prinsipnya AAN merupakan salah satu metode untuk analisis kandungan unsur berdasarkan pada timbulnya radioaktivitas akibat iradiasi dengan menggunakan neutron [1,2,3]. Berdasarkan waktu 
Jurnal Iptek Nuklir Ganendra

Ganendra Journal of Nuclear Science and Technology

Vol. 22 No.2, Juli 2019: 73-84

pengukurannya, teknik Analisis Aktivasi Neutron (AAN) dibedakan menjadi dua kategori yaitu Prompt Gamma Neutron Activation Analysis (PGNAA) dan Delayed Gamma Neutron Activation Analysis (DGNAA). Pada teknik PGNAA sinar gamma diukur selama neutron mengiradiasi sampel, sedangkan pada teknik DGNAA pengukuran dilakukan setelah berakhirnya proses iradiasi [2]. Konsep dasar PGNAA adalah reaksi tangkapan neutron termal yang berasal dari interaksi antara neutron dengan int/materi. Untuk mencapai keadaan yang stabil, inti selanjutnya akan memancarkan sinar gamma dengan energi yang spesifik yaitu prompt gamma (gamma serentak). Sinar gamma serentak adalah suatu radiasi gamma yang dipancarkan secara bersamaan dari suatu radioisotop dengan waktu yang sangat pendek (sekitar $10^{6} \mathrm{~ns}$ ) $[6,7]$. Keunggulan dari PGNAA sendiri dibanding DGNAA adalah dapat mengidentifikasi unsur dengan waktu paruh yang pendek.

Kegiatan pendayagunaan PGNAA di fasilitas reaktor Kartini baik menggunakan sumber neutron isotopik maupun sumber neutron dari beamport reaktor Kartini sudah pernah dilakukan oleh beberapa peneliti, namun memang belum optimal $[8,9,10,11,12]$. Padahal peluang untuk mengembangkan dan menerapkan teknik PGNAA untuk uji kualitas bahan industri sangat menjanjikan karena memiliki beberapa kelebihan bisa dilakukan secara online, portable, dan bersifat tidak merusak. Oleh karena itu, mengingat ketersediaan sarana dan fasilitas yang tersedia di Lab Reaktor Kartini, maka di dalam penelitian ini digunakan sumber neutron isotopik PuBe dan detektor sintilasi NaITI. Tujuan dari penelitian ini ke depannya adalah fasilitas iradiasi Reaktor Kartini dapat memiliki sistem peralatan PGNAA yang bersifat fleksibel dan portable sehingga dapat lebih memudahkan penelitian dan pengujian unsur dengan waktu paruh yang sangat pendek. Pengujian kinerja sistem PGNAA yang meliputi pengukuran fluks neutron sumber $\mathrm{PuBe}$, perancangan container sumber neutron dan penyusunan sistem PGNAA, serta pengujian sistem PGNAA menggunakan bulk sample semen

Perancangan sistem PGNAA membutuhkan serangkaian proses karena melibatkan sumber neutron yang dapat mengaktivasi material. Dalam pemanfaatan zat radioaktif dan sumber radiasi yang memilki risiko tinggi tentunya diperlukan pengawasan agar tidak berbahaya baik bagi pekerja, masyarakat, dan lingkungan sekitar fasilitas iradiasi. PGNAA yang dirancang ini pun telah dilakukan perhitungan agar sesuai dengan peraturan proteksi radiasi agar tidak membahayakan lingkungan. Proteksi radiasi adalah tindakan yang dilakukan untuk mengurangi pengaruh radiasi yang merusak akibat paparan radiasi [13]. Beberapa peraturan yang berkaitan dengan proteksi radiasi ini adalah PERKA BAPETEN Nomor 4 Tahun 2013 dan Keputusan Kepala BAPETEN lainnya $[13,20,21]$. Pada penelitian ini dilakukan perancangan sistem proteksi radiasi yaitu perancangan container sumber neutron. Container ini berfungsi sebagai alat transpot pemindahan sumber neutron dari bulk shielding pool ke fasilitas perangkat air.

Dosis radiasi yang selanjutnya disebut dosis adalah jumlah radiasi yang terdapat dalam medan radiasi atau jumlah energi radiasi yang diserap atau diterima oleh materi yang dilaluinya $[13,14]$. Nilai batas dosis untuk pekerja radiasi yang memperoleh penyinaran seluruh tubuh ditetapkan $20 \mathrm{mSv}$ per tahun, boleh $50 \mathrm{mSv}$ di tahun tertentu asal rata-rata dalam 5 tahun berturutan adalah $20 \mathrm{mSv}$. Peneliti dalam hal ini termasuk dalam kategori magang yaitu seseorang yang menerima latihan dan petunjuk dalam melaksanakan suatu pekerjaan yang memerlukan keahlian khusus. Nilai batas dosis (NBD) untuk para magang dan siswa yang berumur serendahrendahnya 18 tahun, yang sedang melaksanakan latihan atau kerja praktek, atau yang karena keperluan pendidikannya terpaksa menggunakan sumber radiasi pengion, maka NBD yang berlaku adalah sama dengan NBD untuk pekerja radiasi [13].

\section{METODOLOGI}

\section{Material Sampel}

Penelitian ini menggunakan semen portland sebagai sampelnya karena merupakan salah satu dari jenis bulk sample yang mudah didapatkan yang banyak beredar dan digunakan oleh masyarakat dan juga dapat dibandingkan hasil pengujiannya nanti dengan komposisi yang telah dicantumkan dari pabrik pembuatnya. Semen portland merupakan semen yang dihasilkan dengan cara menghaluskan klinker yang terdiri dari silikat kalsium yang bersifat hidrolis dengan bahan tambahan berupa gipsum [15]. Pada penelitian ini menggunakan semen portland merk Tiga Roda sebagai sampel pengujian sistem PGNAA. Komponen-komponen pada analisis kimia semen portland secara umum sesuai dengan SNI 15-2049-2004 tentang Semen Portland dapat dilihat pada Tabel 1 [16]. 
Uji Kinerja Tahap Awal Sistem Prompt Gamma Neutron Activation Analysis (Pgnaa) Menggunakan Sumber Neutron PuBe Untuk Uji Kualitas Semen. (Fahma Roswita, dkk.)

Tabel 1. Komponen Analisis Kimia Semen Portland [11].

\begin{tabular}{cc}
\hline Komponen Mayor & Komponen Minor \\
\hline $\mathrm{SiO}_{2}$ (Silikon Dioksida) & $\mathrm{Na}_{2} \mathrm{O}$ (Natrium Oksida) \\
\hline $\mathrm{Al}_{2} \mathrm{O}_{3}$ (Aluminium Oksida) & $\mathrm{K}_{2} \mathrm{O}$ (Kalium Oksida) \\
\hline $\mathrm{Fe}_{2} \mathrm{O}_{3}$ (Besi (III) Oksida) & $\mathrm{TiO}_{2}$ (Titanium Dioksida) \\
\hline $\mathrm{CaO}$ (Kalsium Oksida) & $\mathrm{P}_{2} \mathrm{O}_{5}$ (Posfor Pentaoksida) \\
\hline $\mathrm{MgO}$ (Magnesium Oksida) & $\mathrm{ZnO}$ (Seng Oksida) \\
\hline $\mathrm{SO}_{3}$ (Sulfur Trioksida) & Sulfida Sulfur \\
\hline Hilang Pijar & $\mathrm{Mn}_{2} \mathrm{O}_{3}$ (Mangan Oksida)
\end{tabular}

\section{Pengukuran Fluks Neutron}

Dalam perhitungan dosis diperlukan data fluks neutron. Oleh karena itu sebelum perancangan dan penyusunan sistem PGNAA terlebih dahulu dilakukan pengukuran fluks neutron menggunakan metode aktivasi. Metode aktivasi adalah suatu cara untuk mendeteksi neutron. Caranya dengan meletakkan suatu material di dalam medan neutron sehingga akan terjadi reaksi antara inti atom dengan neutron. Akibat dari reaksi tersebut maka inti akan terangsang atau berubah menjadi inti lain yang radioaktif, disertai pancaran zarah $a, \beta, \gamma$ atau dapat pula terjadi pancaran zarah-zarah $\beta$ dan $y$ atau a dan y secara serentak [2,3]. Dari hasil iradiasi atau aktivasi tersebut kemudian dapat dihitung aktivitas dari sampel yang diaktivasi. Nilai dari aktivitas sampel ini kemudian menjadi salah satu variabel dari perhitungan fluks neutron.

Untuk menghitung aktivitas dari keping-keping yang diakibatkan oleh neutron termal saja, pada umumnya digunakan kadmium untuk menutupi keping tersebut. Tampang absorbsi kadmium mempunyai harga besar pada energi neutron yang rendah sampai dengan $0,4 \mathrm{eV}$. Jadi praktis semua neutron termal akan diserap oleh kadmium, sehingga aktivitas keping yang diakibatkan oleh neutron termal sama dengan aktivitas keping tanpa dibungkus kadmium dikurangi dengan aktivitas keping terbungkus kadmium.

Pengukuran fluks neutron dilakukan menggunakan metode aktivasi dengan sampel yaitu keping emas $(\mathrm{Au})$. Terdapat 8 keping emas yang digunakan dengan 4 keping emas diantaranya dibungkus kadmium (Cd). Tiap keping emas kemudian dimasukkan ke dalam kantong plastic dan diletakkan pada sebuah rangka aluminium segi delapan (jarring laba-laba) pada jarak tertentu yaitu pada jarak $5 \mathrm{~cm}, 10 \mathrm{~cm}, 15 \mathrm{~cm}$, dan $20 \mathrm{~cm}$ yang dapat dilihat pada skema Gambar 1. Kemudian rangka aluminium segi delapan dimasukkan ke dalam bulk shielding pool dan memposisikan sumber neutron PuBe pada tengah rangka aluminium sehingga dapat mengaktivasi sampel keping emas. Iradiasi dilakukan selama 2 hari.

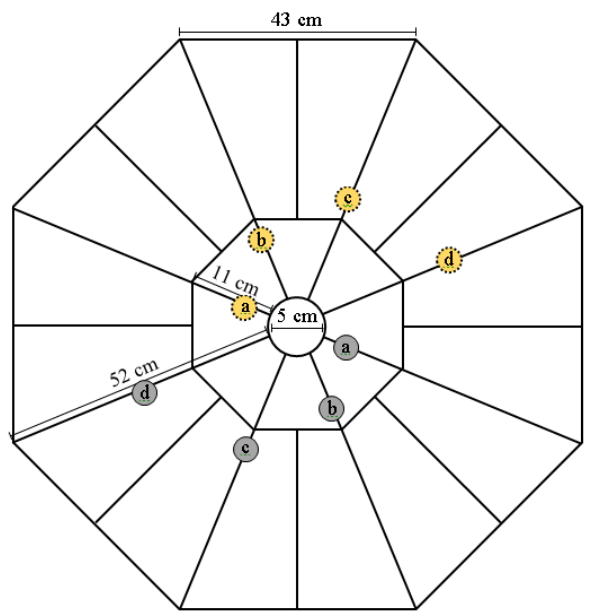

Keterangan:

O = foil emas dibungkus kadmium

= foil emas

a $=$ diletakkan pada jarak $5 \mathrm{~cm}$ dari sumber neutron

$\mathrm{b}=$ diletakkan pada jarak $10 \mathrm{~cm}$ dari sumber neutron

c = diletakkan pada jarak $15 \mathrm{~cm}$ dari sumber neutron

$\mathrm{d}=$ diletakkan pada jarak $20 \mathrm{~cm}$ dari sumber neutron

Gambar 1. llustrasi Rangka Aluminium Segi Delapan (Jaring Laba-Laba).

Keping emas yang telah diiradiasi selama 2 hari kemudian diangkat dan dicacah selama 10 menit dengan menggunakan detektor $\mathrm{Nal}(\mathrm{TI})$. Setelah dicacah kemudian dilakukan perhitungan aktivitas dari masing-masing 
sampel keping emas menggunakan persamaan (1). Hasil perhitungan aktivitas ini digunakan untuk perhitungan pengukuran fluks neutron.

$$
A_{s}=\frac{\lambda C}{\left(1-e^{\left.-\lambda t_{1}\right) e^{-\lambda\left(t_{2}-t_{1}\right)}\left[1-e^{-\lambda\left(t_{3}-t_{2}\right)}\right]}\right.}
$$

dengan $\lambda$ adalah tetapan peluruhan, $C$ adalah jumlah cacah selang waktu $\left(t_{3}-t_{2}\right), t_{1}$ adalah lamanya irradiasi, $t_{2}$ adalah waktu mulainya pencacahan, $\mathrm{t}_{3}$ adalah waktu akhir pencacahan, dan $\mathrm{t}_{2}-\mathrm{t}_{1}$ adalah waktu tunggu.

Penelitian ini melakukan perhitungan fluks neutron untuk masing-masing fluks neutron total, fluks neutron cepat, dan fluks neutron termal. Untuk fluks neutron total dapat dihitung dari keping emas tanpa selubung kadmium. Untuk fluks neutron cepat dihitung dari keping emas yang diberi selubung kadmium. Perhitungan fluks neutron menggunakan persaamaan (2) sebagai berikut:

$$
\Phi=\frac{A_{s} \rho}{K \Sigma_{a} m}
$$

dengan $\Phi$ adalah kecepatan fluks neutron (neutron $/ \mathrm{cm}^{2} \mathrm{~s}$ ), $A_{s}$ adalah aktivitas sampel emas (dps), $\rho$ adalah massa jenis emas $\left(\mathrm{gram} / \mathrm{cm}^{3}\right), K$ adalah efisiensi detektor, $\Sigma_{a}$ adalah tampang lintang makroskopis absorbsi (cm1), dan $m$ adalah massa keping emas (gram).

\section{Perancangan Container Sumber Neutron dan Penyusunan Sistem Prompt Gamma Neutron Activation Analysis (PGNAA)}

Perancangan sistem PGNAA meliputi perancangan container sumber neutron, system perangkat air sebagai perisai dan kolimator neutron. Container sumber neutron dimaksudkan agar pada saat pemindahan sumber neutron dari bulk shielding pool ke fasilitas perangkat air tetap aman dan selamat sehingga tidak membahayakan peneliti, pekerja, dan lingkungan sekitar. Setelah mengetahui nilai fluks neutron dari sumber neutron PuBe yang akan dipindahkan, dilakukan perhitungan untuk membuat desain container sumber neutron yang terbuat dari ember cat bekas yang diisi dengan air. Pengisian air dilakukan karena air merupakan moderator neutron yang paling baik dan paling mudah didapat. Setelah itu dilakukan perancangan sistem PGNAA yang dapat dilihat pada Gambar 2 berikut.

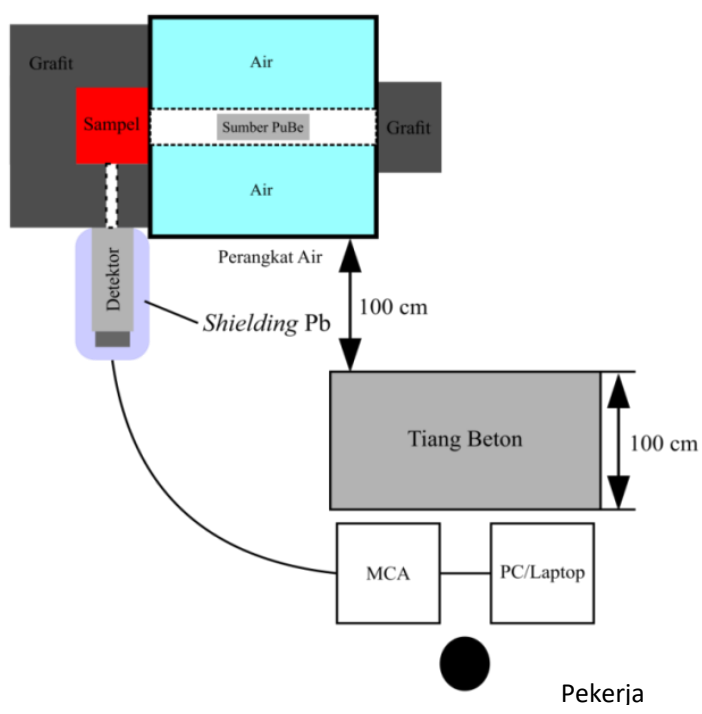

Gambar 2. Skema Perancangan Sistem Prompt Gamma Neutron Activation Analysis (PGNAA) Tampak dari Atas

Dalam penyusunan sistem PGNAA perhitungan yang dilakukan tidak jauh berbeda dengan perancangan container sumber neutron. Hanya saja pada beberapa titik moderator yang digunakan bukanlah air melainkan 
grafit. Hal ini dilakukan dengan pertimbangan bahwa grafit dapat memantulkan neutron kembali. Persamaan nilai fluks neutron setelah melalui suatu media dapat ditunjukkan pada persamaan (3) berikut:

$$
\Phi=\Phi_{0} e^{-x x}
$$

dengan $\Phi$ adalah fluks neutron setelah melalui suatu media, $\Phi_{0}$ adalah fluks neutron mula-mula, $\Sigma$ adalah tampang lintang makroskopis material perisai $\left(\mathrm{cm}^{-1}\right)$, dan $x$ adalah tebal media yang digunakan $(\mathrm{cm})$.

Setelah diperoleh intensitas fluks neutron yang melalui suatu media, kemudian dilakukan perhitungan konversi dari nilai fluks neutron ke dosis. Hal ini akan memberikan gambaran apakah dosis yang diperoleh untuk peneliti melebihi nilai batas dosis (NBD) atau tidak. Jika melebihi dari NBD maka perlu dilakukan variasi jarak dan waktu agar penelitian tetap berjalan dengan aman dan selamat. Laju dosis neutron dapat ditentukan dengan mengalihkan fluks neutron dengan faktor konversi dosis dengan persamaan $(4)[17,18]$.

$$
H=\Phi \times h_{p, s i a b}
$$

Dengan $H$ adalah laju dosis ekuivalen ( $\mu$ Sv/jam), $\Phi$ adalah fluks neutron $\left(\mathrm{n} \mathrm{cm}^{-2} \mathrm{~s}^{-1}\right)$, dan $\mathrm{h}_{\mathrm{p}, \text { slab }}$ faktor konversi $\left(4,75 \times 10^{-5} \mu \mathrm{Sv} \mathrm{cm}^{2} \mathrm{n}^{-1}\right)$.

Nilai faktor konversi yang digunakan pada penelitian ini adalah $4,75 \times 10^{-5} \mu \mathrm{Sv}_{\mathrm{cm}} \mathrm{cm}^{-1}$, nilai ini adalah nilai dari perbandingan fluks neutron dan laju dosis dari simulasi Bonne Sphere menggunakan Monte Carlo untuk spektrum neutron dengan sumber ${ }^{252} \mathrm{Cf}$. Dosis yang telah dihitung digunakan sebagai acuan untuk perhitungan perisai radiasi, baik itu pada container sumber neutron maupun pada sistem PGNAA yang dibuat.

\section{Pengujian Sistem PGNAA Menggunakan Bulk Sample Semen}

Pada PGNAA pencacahan sampel dilakukan saat iradiasi berlangsung sehingga unsur yang memiliki waktu paruh pendek dapat langsung tercacah sebelum meluruh. Analisis kualitatif dilakukan dengan mengidentifikasi puncak-puncak spektrum energi pada sampel semen yang muncul saat proses pencacahan berlangsung. Kemudian puncak-puncak spektrum energi tersebut dicocokkan dengan daftar energi sinar gamma. Hal yang perlu diperhatikan pada saat analisis kualitatif adalah adanya penimbunan puncak pada nuklida-nuklida yang memiliki selisih spektrum energi sangat kecil. Untuk saat ini nuklida umur sangat pendek belum bisa dilakukan mengingat masih banyak noise dan detektor gamma NalTI memiliki daya pisah relatif kurang baik dibanding detector jenis GeLi atau HpGe, walaupun demikian untuk bulk sample semen masih bisa dideteksi karena kandungan radionuklidanya memiliki umur paroh yang relatif panjang.

Dalam software Genie 2000 identifikasi puncak spektrum energi dapat diketahui dengan menggunakan pilihan Nuclide Identification pada menu Analyze. Namun sebelumnya perlu dilakukan pengaturan kalibrasi dan identifikasi puncak. Informasi dari analisis kualitatif ini sangat berguna apabila akan melakukan analisis kuantitatif. Selain menggunakan software Genie 2000 untuk identifikasi puncak spektrum energi, pengecekan puncak spektrum energi juga dilakukan secara manual dengan melihat tabel energi pada Gamma-Rays of Radionuclides in Order of Increasing Energy [19]. Hasil kemudian dicocokkan dengan aplikasi JANIS. JANIS (Java-based Nuclear Information Software) adalah program yang dirancang untuk memfasilitasi visualisasi dan manipulasi data nuklir. Bentuknya berupa tabel unsur periodik yang dilengkapi dengan spesifikasi masing-masing karakteristik unsurnya.

\section{HASIL DAN PEMBAHASAN}

Sebelum melakukan perhitungan fluks neutron, terlebih dahulu diperlukan perhitungan aktivitas sampel keping emas $(\mathrm{Au})$ yang telah diiradiasi dengan sumber neutron isotopik PuBe. Peneliti menggunakan 4 keping emas terbuka dan 4 keping emas yang dibungkus kadmium dengan divariasikan jaraknya yaitu $5 \mathrm{~cm}, 10 \mathrm{~cm}, 15$ $\mathrm{cm}$, dan $20 \mathrm{~cm}$. Keping-keping emas tersebut dipasang pada perangkat aluminium segi delapan (jaring laba-laba) sebagai penahan keping emas agar tidak mudah lepas saat dimasukkan ke dalam Bulk Shielding Pool. Sampel keping emas diaktivasi selama 2 hari di dalam Bulk Shielding Pool. Setelah 2 hari, sampel keping emas diambil untuk kemudian dilakukan pencacahan. 
Jurnal Iptek Nuklir Ganendra

Ganendra Journal of Nuclear Science and Technology

Vol. 22 No.2, Juli 2019: 73-84

Perhitungan aktivitas diperoleh dari hasil pencacahan radiasi yang dideteksi oleh detektor $\mathrm{Nal}(\mathrm{TI})$. Keping emas terbuka yang tidak dibungkus kadmium digunakan untuk mengukur fluks neutron total. Sedangkan keping emas yang dibungkus kadmium digunakan untuk mengukur fluks neutron cepat. Waktu pencacahan untuk masing-masing sampel keping emas dilakukan selama 10 menit. Hal ini dikarenakan apabila dicacah kurang dari waktu 10 menit, puncak energi untuk Au belum terlihat dan sulit dicari nett area nya sehingga tidak dapat memastikan jumlah cacah nettonya [17, 18].

Tabel 2. Hasil Perhitungan Aktivitas Sampel Keping Emas dengan Selubung Kadmium.

\begin{tabular}{cccccc}
\hline No. Jarak & $\begin{array}{c}\text { Puncak } \\
\text { (cm) }\end{array}$ & $\begin{array}{c}\text { Cacah } \\
\text { Energi } \\
\text { (keV) }\end{array}$ & $\begin{array}{c}\text { Cacah } \\
\text { Netto } \\
\text { (cps) }\end{array}$ & $\begin{array}{c}\text { Aktivitas } \\
\text { (dps) }\end{array}$ \\
\hline 1 & 5 & 471,6 & 504 & 0,84 & 2,1346 \\
\hline 2 & 10 & 444,6 & 498 & 0,83 & 21035 \\
\hline 3 & 15 & 456,8 & 240 & 0,4 & 1,0110 \\
\hline 4 & 20 & 454,8 & 120 & 0,2 & 0,5042 \\
\hline
\end{tabular}

Tabel 3. Hasil Perhitungan Aktivitas Sampel Keping Emas Terbuka.

\begin{tabular}{cccccc}
\hline No. & $\begin{array}{c}\text { Jarak } \\
\text { (cm) }\end{array}$ & $\begin{array}{c}\text { Puncak } \\
\text { Energi } \\
\text { (keV) }\end{array}$ & Cacah & $\begin{array}{c}\text { Cacah } \\
\text { Netto } \\
\text { (cps) }\end{array}$ & $\begin{array}{c}\text { Aktivitas } \\
\text { (dps) }\end{array}$ \\
\hline 5 & 5 & 451,6 & 3504 & 5,84 & 14,6430 \\
\hline 6 & 10 & 453,8 & 2004 & 3,34 & 8,3519 \\
\hline 7 & 15 & 452 & 666 & 1,11 & 2,7682 \\
\hline 8 & 20 & 456,6 & 432 & 0,72 & 1,8101 \\
\hline
\end{tabular}

Tabel 2 dan Tabel 3 menunjukkan hasil perhitungan aktivitas yang telah dilakukan pada 8 sampel keping emas. Data yang ditampilkan juga meliputi puncak energi, cacah, cacah netto per satuan waktu (cps) dan aktivitas dalam satuan dps atau setara dengan becquerel (Bq). Pada peluruhan emas ${ }^{198} \mathrm{Au}$ energi yield tertinggi hingga mencapai 0,9899 berada pada energi $411,8 \mathrm{keV}$. Namun 8 sampel keping emas yang dicacah tidak satupun yang puncak energinya tepat berada pada $411,8 \mathrm{keV}$. Ini kemungkinan dipengaruhi oleh resolusi detektor $\mathrm{Nal}(\mathrm{TI})$ yang memang rendah sehingga kurang mampu membedakan puncak energi.

Peneliti sudah mencoba melakukan pencacahan ulang dengan detektor HPGe yang memiliki resolusi jauh lebih baik dibandingkan dengan detektor Nal(TI) dan hasilnya puncak yang terlihat memang benar berada pada energi sekitar $412 \mathrm{keV}$. Namun penelitian ini tetap menggunakan detektor Nal(TI) karena pada umumnya sistem PGNAA yang memiliki mobilisasi tinggi adalah dengan menggunakan detektor Nal(TI) karena lebih mudah dan praktis dibandingkan dengan detektor HPGe yang lebih besar dan juga membutuhkan suplai nitrogen cair yang tidak dapat digunakan sewaktu-waktu dan harus dipersiapkan terlebih dahulu $[4,6,17,18]$.

Hasil perhitungan aktivitas dari masing-masing keping sampel yang telah dilakukan kemudian digunakan untuk perhitungan nilai fluks neutron. Fluks neutron total diperoleh dari hasil perhitungan pada sampel keping emas terbuka tanpa diberi bungkus selubung kadmium. Fluks neutron cepat diperoleh dari hasil perhitungan sampel keping emas yang diberi bungkus selubung kadmium. Sebelum melakukan pencacahan pada sampel keping emas, terlebih dahulu dilakukan kalibrasi efisiensi. Kalibrasi efisiensi ini berpengaruh pada perhitungan fluks neutron. Puncak energi yang terbaca saat pencacahan dilakukan pada masing-masing sampel keping emas kemudian dimasukkan ke dalam persamaan kalibrasi efisiensi yang telah dilakukan sebelumnya sehingga diperoleh nilai $k$ untuk efisiensi dari masing-masing sampel keping emas.

Nilai untuk masing-masing fluks neutron total, fluks neutron cepat, nilai banding kadmium, dan fluks neutron termal dapat dilihat pada Tabel 4. Hasil perbandingan antara fluks neutron total dan fluks neutron cepat merupakan nilai banding kadmium yang menjadi dasar untuk perhitungan fluks neutron termal. Sehingga fluks neutron termal dapat diperoleh dari perkalian antara fluks neutron cepat dengan nilai banding kadmium dikurang 
Uji Kinerja Tahap Awal Sistem Prompt Gamma Neutron Activation Analysis (Pgnaa) Menggunakan Sumber Neutron PuBe Untuk Uji Kualitas Semen. (Fahma Roswita, dkk.)

1. Oleh karena itu, nilai fluks neutron termal juga dapat diperoleh dari hasil pengurangan antara fluks neutron total dengan fluks neutron cepat.

Tabel 4. Hasil Perhitungan Fluks Neutron Total, Fluks Neutron Cepat, Nilai Banding Kadmium.

\begin{tabular}{ccccc}
\hline $\begin{array}{c}\text { Jarak } \\
(\mathbf{c m})\end{array}$ & $\begin{array}{c}\text { Fluks Neutron } \\
\text { Total }^{*}\end{array}$ & $\begin{array}{c}\text { Fluks Neutron } \\
\text { Cepat }^{*}\end{array}$ & $\begin{array}{c}\text { Fluks Neutron } \\
\text { Termal }^{*}\end{array}$ & $\begin{array}{c}\text { Nilai Banding } \\
\text { Kadmium }\end{array}$ \\
\hline 5 & 16010 & 2334 & 13676 & 6,8595 \\
\hline 10 & 9132 & 2300 & 6832 & 3,9704 \\
\hline 15 & 3027 & 1105 & 1922 & 2,7394 \\
\hline 20 & 1979 & 551,2 & 1467,8 & 3,8713
\end{tabular}

*satuan fluks neutron dalam $\mathrm{ncm}^{-2} \mathrm{~s}^{-1}$

Tabel 4 menunjukkan bahwa untuk fluks neutron termal pada jarak $5 \mathrm{~cm}, 10 \mathrm{~cm}, 15 \mathrm{~cm}$, dan $20 \mathrm{~cm}$ berturut-turut adalah $13676 \mathrm{n} \mathrm{cm}^{-2} \mathrm{~s}^{-1}, 6832 \mathrm{n} \mathrm{cm}^{-2} \mathrm{~s}^{-1}, 1922 \mathrm{n} \mathrm{cm}^{-2} \mathrm{~s}^{-1}$, dan $1467,8 \mathrm{n} \mathrm{cm}^{-2} \mathrm{~s}^{-1}$. Sehingga dapat dikatakan bahwa untuk rata-rata nilai fluks neutron yang diperoleh dari metode aktivasi neutron berada pada orde $10^{4} \mathrm{n} \mathrm{cm}^{-2} \mathrm{~s}^{-1}$.

Telah dilakukan perancangan desain container sumber neutron sebagai media untuk memindahkan sumber neutron yang semula berada pada bulk shielding pool ke dalam perangkat air yang digunakan untuk sistem pengujian Prompt Gamma Neutron Activation Analysis (PGNAA) yang dapat dilihat pada Gambar 3 dan Gambar 4. Perhitungan fluks neutron setelah melalui perisai radiasi berupa air dilakukan dengan menggunakan hasil perhitungan fluks neutron pada Tabel 4. Untuk perhitungannya digunakan nilai fluks neutron yang paling besar yaitu dengan pada jarak $5 \mathrm{~cm}$. Setelah diperoleh nilai fluks neutron yang telah melalui media perisai radiasi berupa air, kemudian dilakukan perhitungan laju dosis radiasi untuk masing-masing posisi $A, B$, dan $C$ yang terdapat pada Gambar 3 dan Gambar 4. Hasil perhitungan nilai fluks neutron dan laju dosis radiasi dapat dilihat pada Tabel 5.

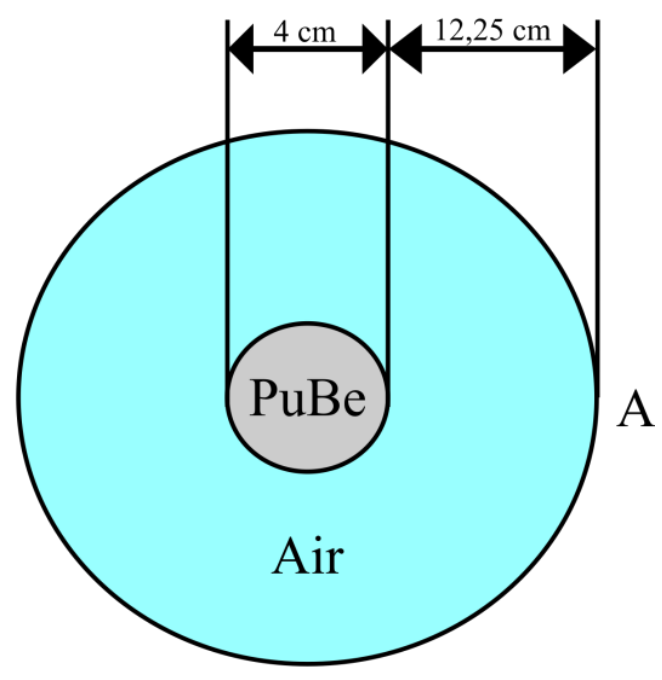

Gambar 3. Container Air Tampak Atas.

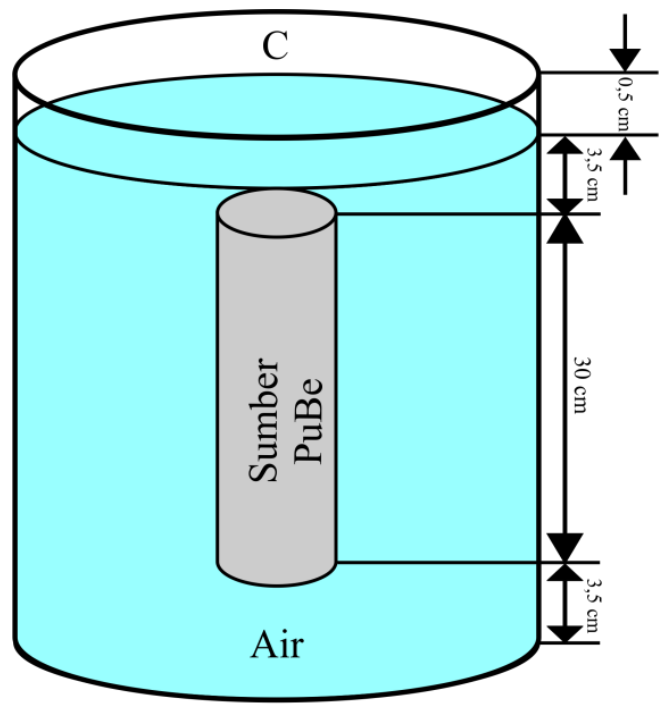

$\mathrm{B}$

Gambar 4. Container Air Tampak Samping.

Perhitungan pada Tabel 5 menunjukkan bahwa laju dosis radiasi yang paling tinggi berada pada posisi $\mathrm{B}$ yaitu di bawah container dengan jarak terkecil sebesar 3,5 cm. Besar laju dosis yang diperoleh yaitu 2165,3 $\mu \mathrm{Sv} / \mathrm{jam}$ atau senilai dengan $2,1653 \mathrm{mSv} / \mathrm{jam}$. Apabila dibandingkan dengan NBD yang ada pada peraturan BAPETEN $[13,19,20]$ yaitu sebesar $20 \mathrm{mSv} /$ tahun atau 2,283 $\times 10^{-3} \mathrm{mSv} / \mathrm{jam}$ (jika diasumsikan secara konservatif waktu kerja sama dngan waktu kalender selama setahun), dosis tersebut termasuk berada di atas 
batas dosis (NBD). Sehingga proses pemindahan dari sumber neutron dilakukan di bawah pengawasan langsung petugas proteksi radiasi dan dilakukan dalam waktu yang cukup singkat yaitu sekitar 15 menit.

Tabel 5. Hasil Perhitungan Fluks Neutron dan Laju Dosis pada Container Sumber Neutron.

\begin{tabular}{ccc}
\hline Posisi & $\begin{array}{c}\text { Fluks Neutron } \\
\left(\mathbf{n} \mathbf{~ c m}^{-2} \mathbf{s}^{-1}\right)\end{array}$ & $\begin{array}{c}\text { Laju Dosis } \\
(\boldsymbol{\mu} \text { Sv/jam })\end{array}$ \\
\hline A & 10445,2 & 1786,1 \\
\hline B & 12662,5 & 2165,3 \\
\hline C & 12661,8 & 2165,2 \\
\hline
\end{tabular}

Nilai laju dosis yang berada pada daerah kerja petugas berada pada posisi A yaitu 1,7861 mSv/jam. Untuk durasi kerja pemindahan sumber neutron selama 15 menit, dosis yang diterima sebesar 0,447 mSv. Menurut peraturan batas penyinaran maksimum adalah sebesar $0,1 \mathrm{R} /$ minggu senilai dengan $1 \mathrm{mSv} / \mathrm{minggu}$ pada daerah terkontrol. Pemindahan sumber neutron hanya dilakukan sekali dalam 1 minggu dan 2 kali dalam 1 bulan pada kasus penelitian ini, sehingga dosis sebesar $0,447 \mathrm{mSv}$ masih sesuai dengan peraturan yang berlaku.

Setelah perancangan sistem transpot sumber neutron siap, maka dilakukan pemindahan sumber neutron dari bulk shielding pool ke dalam perangkat air yang akan digunakan. Ilustrasi perangkat air dapat dilihat pada Gambar 5. dan Gambar 6.

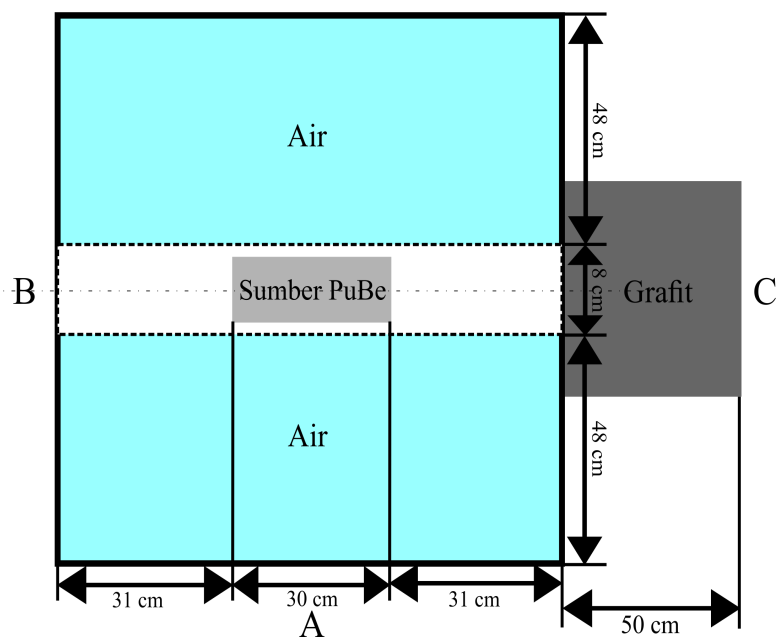

Gambar 5. Perangkat Air Tampak Atas.

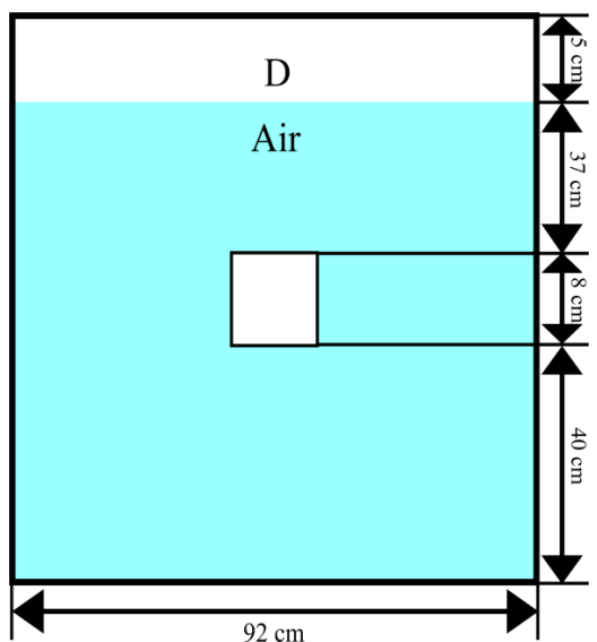

Gambar 6. Perangkat Air Tampak Samping.

Perangkat air diisi dengan air demineral yaitu air yang memiliki kandungan mineral yang sedikit. Air demineral dipilih karena memiliki kandungan mineral yang sedikit sehingga meminimalisir unsur yang berada dalam air ikut teraktivasi dan menganggu sistem PGNAA. Dari hasil perhitungan yang ditampilkan pada Tabel 6 dapat dilihat bahwa yang memiliki nilai fluks neutron dan laju dosis paling tinggi terletak pada posisi $B$ dan $C$. Posisi B nantinya digunakan untuk meletakkan sampel semen yang akan diuji, sehingga jika fluks neutronnya masih tinggi berarti kemampuan neutron untuk mengaktivasi sampel akan semakin baik. Pada posisi $\mathrm{C}$ merupakan ujung lubang perangkat air yang kemudian ditutup dengan balok grafit setebal $50 \mathrm{~cm}$. Untuk posisi $\mathrm{C}$ nilai laju dosisnya hampir sama dengan posisi $B$. Namun pada penyusunan perangkat PGNAA ini posisi $C$ langsung menghadap dinding beton sehingga walaupun laju dosisnya cukup tinggi diantara posisi lain, posisi $\mathrm{C}$ tidak akan membahayakan dikarenakan tidak mungkin ada aktivitas para pekerja di sekitar posisi $\mathrm{C}$ tersebut. 
Tabel 6. Hasil Perhitungan Fluks Neutron dan Laju Dosis pada Perangkat Air.

\begin{tabular}{ccc}
\hline Posisi & $\begin{array}{c}\text { Fluks Neutron } \\
\left(\mathbf{n} \mathbf{~ c m}^{-2} \mathbf{s}^{-1}\right)\end{array}$ & $\begin{array}{c}\text { Laju Dosis } \\
(\boldsymbol{\mu} \text { Sv/jam })\end{array}$ \\
\hline A & 4757,12 & 813,47 \\
\hline B & 13633,9 & 2331,4 \\
\hline D & 13515,8 & 2311,2 \\
\hline D & 6059,59 & 1036,2 \\
\hline
\end{tabular}

Posisi A yang berada samping perangkat air memiliki fluks neutron dan laju dosis paling kecil karena merupakan bagian dengan perisai air paling tebal. Keliling perangkat air juga diberi lapisan timbal untuk menyerap sinar gamma yang timbul akibat aktivasi neutron. Hal ini sangat penting karena pada posisi $\mathrm{A}$ merupakan daerah tempat yang sering dilalui oleh para pekerja dan petugas proteksi radiasi. Gambar 2 di atas (Bab Metodologi) menunjukkan letak posisi pekerja berada. Jarak antara tepi perangkat air dengan pekerja adalah $2 \mathrm{~m}$, dengan $1 \mathrm{~m}$ adalah tebal tiang beton dan $1 \mathrm{~m}$ adalah jarak tiang beton dengan perangkat air.

Nilai laju dosis posisi A sebesar $813,47 \mu \mathrm{Sv} / \mathrm{jam}$ atau senilai $0,8135 \mathrm{mSv} / \mathrm{jam}$ yang berada di atas batas dosis efektif sebesar $20 \mathrm{mSv} /$ tahun atau 2,283 $\times 10^{-3} \mathrm{mSv} / \mathrm{jam}$ menurut peraturan BAPETEN $[13,19,20]$. Namun untuk posisi pekerja dan petugas pencacahan masih berada cukup jauh dari posisi $A$ dan dilindungi oleh tiang beton setebal $1 \mathrm{~m}$ yang berjarak $1 \mathrm{~m}$ dari perangkat air. Waktu maksimal dibatasi sehingga tidak berada cukup lama di daerah sekitar posisi $\mathrm{A}$, sehingga probabilitas menerima dosis paparannya pun semakin kecil. Jika dihitung maka nilai laju dosis pada posisi pekerja sebesar 1,098 $\times 10^{-4} \mathrm{mSv} / \mathrm{jam}$.. Nilai laju dosis tersebut berada di bawah nilai batas dosis menurut peraturan BAPETEN $[13,19,20]$ dan juga IAEA [21]

Untuk pengujian sistem PGNAA sumber neutron isotopik PuBe dipindahkan dari bulk shielding pool ke dalam perangkat air. Sebelumnya sumber neutron diberi wadah berupa pipa PVC yang sudah diberi benang nilon dengan maksud agar mudah dalam mobilisasi sumber neutron. Setelah berada di dalam perangkat air, satu lubang pada perangkat air ditutup dengan grafit dan lubang lainnya dibiarkan terbuka sebagai tempat meletakkan sampel semen. Sampel semen diletakkan persis di mulut lubang perangkat air yang kemudian di sekelilingnya ditutup dengan grafit dan timbal sebagai perisai radiasi. Sebagai pengujian awal, sampel diiradiasi sekaligus dicacah selama 1 jam sehingga sampel diyakini sudah teraktivasi sepenuhnya. Spektrum hasil pencacahan sampel semen yang diaktivasi sumber neutron PuBe dapat dilihat pada Gambar 7. berikut.

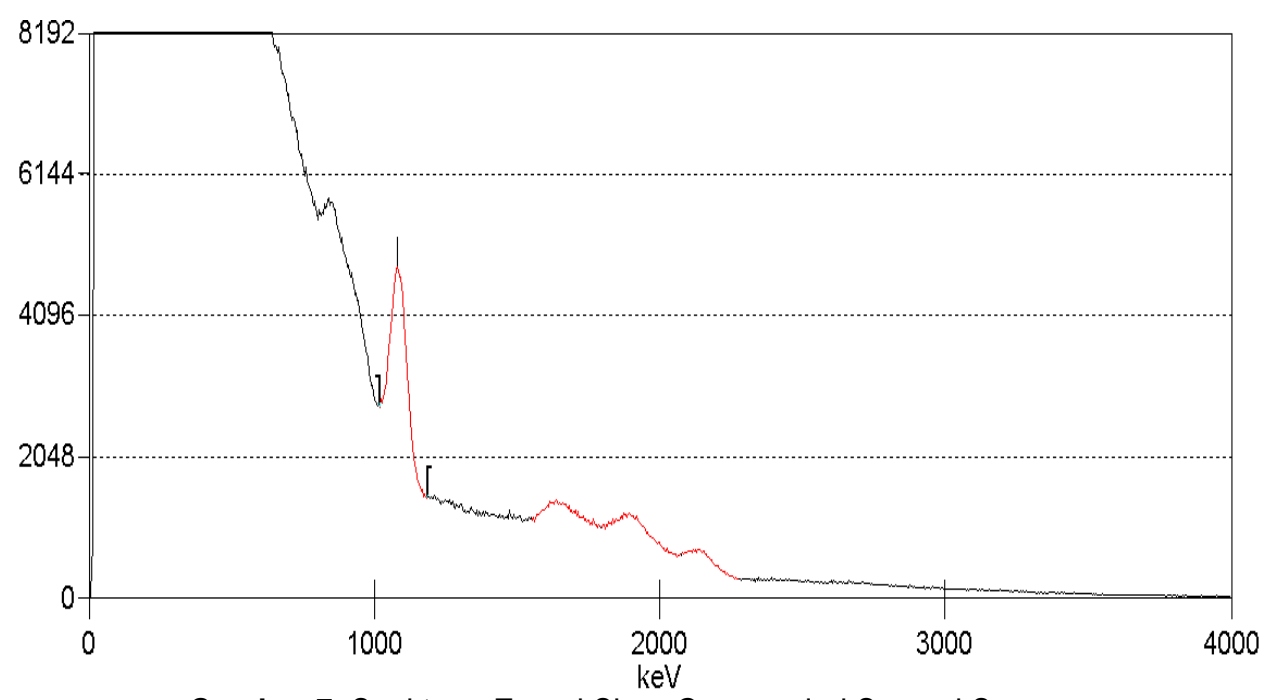

Gambar 7. Spektrum Energi Sinar Gamma dari Sampel Semen.

Pada spektrum tersebut perlu dilakukan perbesaran sehingga mampu menampilkan beberapa puncak energi dari spektrum energi yang tercacah. Terdapat 4 puncak yang dapat terbaca pada spektrum. Keempat puncak ini berada dikisaran energi $1000 \mathrm{keV}$ hingga $2500 \mathrm{keV}$. Sebagai pedoman awal, beberapa energi unsur yang terdapat pada sampel semen memang berada pada kisaran energi tersebut seperti Si, Fe, S, Ca, Mg, dan 
Jurnal Iptek Nuklir Ganendra

Ganendra Journal of Nuclear Science and Technology

Vol. 22 No.2, Juli 2019: 73-84

Al $[15,16,18]$. Namun tidak semua unsur mampu menampilkan puncak spektrum energi. Analisis puncak energi dilakukan dengan software Genie 2000 yang ditampilkan pada Gambar 8, di mana dari Gambar 8 dapat dilihat bahwa energi dari keempat puncak energi teridentifikasi oleh library pada software Genie 2000, tetapi terjadi pergeseran puncak. Oleh karena itu peneliti kemudian melakukan analisis kualitatif secara manual dengan mencocokkan unsur yang terkandung pada semen dengan puncak energi yang ditampilkan pada spektrum menggunakan data base energi gamma.

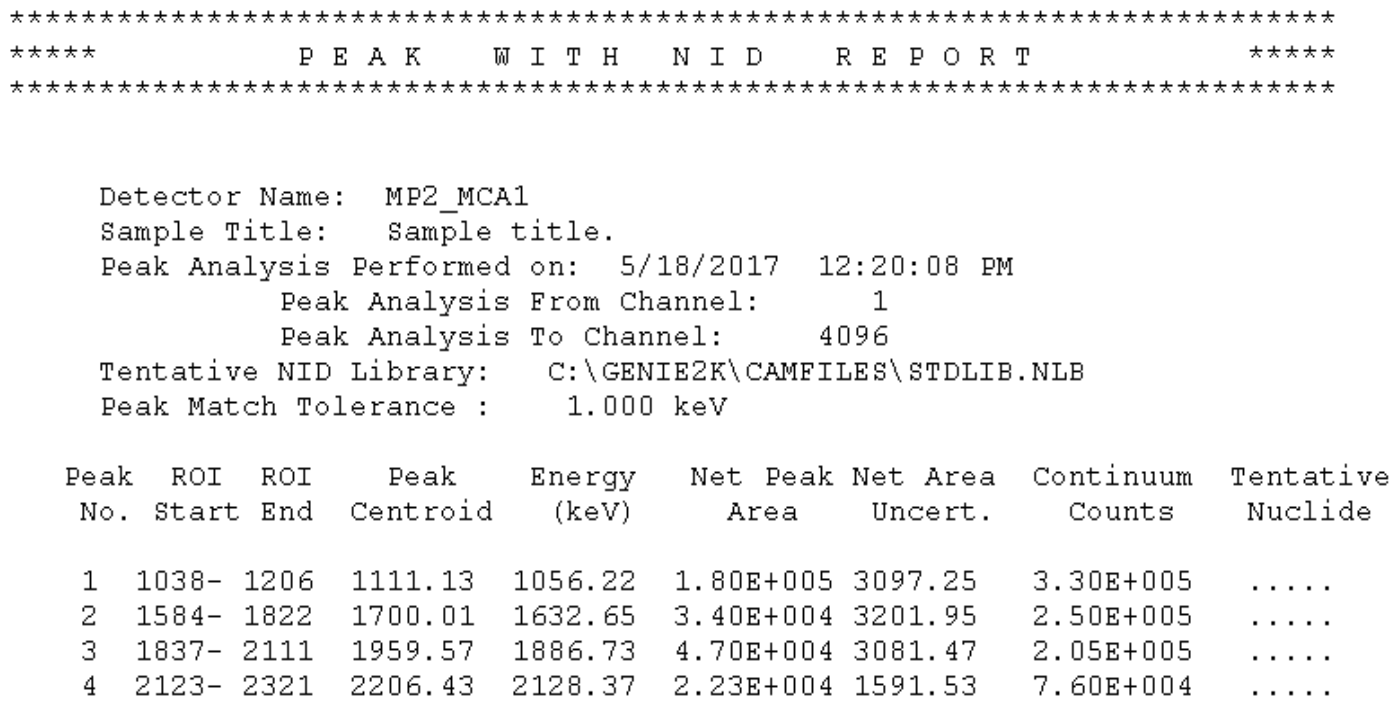

Gambar 8. Info Analisis Nuklida dari Spektrum Energi Sampel Semen dengan Software Genie 2000

Pada puncak pertama yang berenergi 1056,22 keV kemungkinan merupakan puncak energi milik ${ }^{59} \mathrm{Fe}$ yang pada tabel energi berada pada 1098,6 keV. Ini menandakan bahwa puncak energi yang ditampilkan spektrum mengalami pergeseran. Puncak energi kedua pada 1632,65 keV kemungkinan merupakan puncak energi milik ${ }^{28} \mathrm{Al}$ yang pada tabel energi berada pada $1773,9 \mathrm{keV}$.

Untuk puncak energi ketiga sebesar $1886,73 \mathrm{keV}$ pada tabel energi tidak terdapat unsur yang sesuai pada unsur mayor sampel semen. Kemungkinan pada energi ini merupakan puncak energi milik unsur minor sampel semen yaitu ${ }^{63} \mathrm{Zn}$ yang puncak energinya terletak pada $1890 \mathrm{keV}$ dan ${ }^{25} \mathrm{Na}$ yang puncak energinya terletak pada $1960 \mathrm{keV}$. Kedua energi tersebut karena berdekatan maka detektor Nal(TI) tidak dapat membedakan puncak energi keduanya. Sehingga menyebabkan dua unsur minor pada sampel semen tersebut berada pada puncak energi yang sama dengan rentang energi pada puncak energi ketiga adalah $1837 \mathrm{keV}$ sampai $2111 \mathrm{keV}$. Selain itu besar kemungkinan terdapat material lain di sekitar sistem PGNAA yang ikut teraktivasi misalnya adalah toples tempat sampel, grafit, atau bahan dari bak air yang kemudian ikut membentuk puncak energi di rentang energi tersebut.

Pada puncak energi keempat 2128,37 keV jika dilihat pada tabel energi tidak terdapat unsur yang sesuai dengan unsur mayor sampel semen. Kemungkinan energi ini milik ${ }^{56} \mathrm{Mn}$ yang merupakan unsur minor pada semen yang pada tabel energi terletak pada energi $2113 \mathrm{keV}$. Puncak energi keempat ini dapat juga merupakan unsur milik material lain yang berada di sekitar sistem PGNAA yang ikut teraktivasi. Namun akibat keterbatasan detektor $\mathrm{Nal}(\mathrm{TI})$ yang tidak mampu membedakan energi dengan baik maka terdapat timbunan energi di sekitar energi $2123 \mathrm{keV}$ hingga $2321 \mathrm{keV}$, sehingga terdapat banyak kemungkinan unsur yang terdapat diantara rentang energi tersebut. Analisis kualitatif keempat puncak energi tersebut dapat dilihat pada Tabel 7 berikut. 


\begin{tabular}{|c|c|c|c|c|c|}
\hline $\begin{array}{c}\text { ROI Awal } \\
\text { (keV) }\end{array}$ & $\begin{array}{l}\text { ROI Akhir } \\
\quad(\mathrm{keV})\end{array}$ & $\begin{array}{c}\text { Energi yang } \\
\text { Terbaca } \\
\text { (keV) }\end{array}$ & $\begin{array}{c}\text { Energi yang } \\
\text { Terdapat pada } \\
\text { Database (keV) }\end{array}$ & Jenis Unsur & $\begin{array}{l}\text { Waktu Paruh } \\
\text { Unsur }\end{array}$ \\
\hline 1038 & 1206 & 1056,22 & 1098,6 & ${ }^{59} \mathrm{Fe}$ & 44,45 hari \\
\hline 1584 & 1822 & 1632,65 & $1773,9$. & ${ }^{28} \mathrm{Al}$ & 2,24 menit \\
\hline \multirow[t]{2}{*}{1837} & 2111 & 1886,73 & 1890 & $63 \mathrm{Zn}$ & 38,47 menit \\
\hline & & & 1960 & ${ }^{25} \mathrm{Na}$ & 59,10 detik \\
\hline 2123 & 2321 & 2128,37 & 2113 & $56 \mathrm{Mn}$ & 2,58 hari \\
\hline
\end{tabular}

Kelima unsur yang teridentifikasi memiliki waktu paruh (half time) masing-masing yang ditunjukkan pada Tabel 7. Dilihat dari waktu paruhnya, dapat diketahui bahwa beberapa unsur yang berasal dari aktivasi prompt gamma (gamma serentak) adalah ${ }^{28} \mathrm{Al}$ dan ${ }^{25} \mathrm{Na}$. Hal ini dikarenakan kedua unsur tersebut memiliki waktu paruh yang sangat pendek sehingga tidak mungkin dideteksi dengan metode DGNAA.

Tidak teridentifikasinya unsur-unsur nuklida dari hasil pencacahan sampel semen bisa disebabkan oleh banyak faktor diantaranya penggunaan jenis detektor di mana pada penelitian awal ini detektor yang digunakan adalah jenis $\mathrm{Nal}(\mathrm{TI})$ yang memiliki resolusi rendah, dan pengaturan pada sistem MCA. Hal ini dikarenakan kemampuan resolusi detektor berpengaruh besar pada pembacaan pada puncak energi yang berdekatan, sehingga bisa saja hasil puncak energi yang ditampilkan pada spektrum merupakan gabungan dari beberapa puncak energi dari beberapa unsur. Selain itu sistem pengaturan MCA juga sangat berperan aktif dalam hasil pencacahan. Pergeseran puncak-puncak energi pada nomor kanal tertentu bisa disebabkan oleh pengaturan overall gain dan juga pengaturan kalibrasi pada sistem software MCA. Semakin besar overall gain maka akan semakin lebar dan semakin bergeser ke kanan puncak energinya. Ketelitian pengaturan instrumentasi nuklir dengan sistem lain misalkan dengan instalasi listrik dan sejenisnya tentu juga mempengaruhi proses pencacahan pada saat penelitian.

\section{KESIMPULAN}

Perancangan dan pembuatan sistem PGNAA berbasis sumber neutron isotopik PuBe telah memenuhi peraturan BAPETEN yaitu laju dosis pada wilayah kerja pekerja radiasi berkisar $0,1098 \mu \mathrm{Sv} / \mathrm{jam}$ yang berada di bawah batas dosis sebesar $20 \mathrm{mSv} /$ tahun atau 2,283 $\mu \mathrm{Sv} / \mathrm{jam}$ (jika diambil setahun $8760 \mathrm{jam}$ ). Nilai fluks neutron rerata terukur dari sumber neutron PuBe pada jarak 5-10 cm berorde $10^{4} \mathrm{n} \mathrm{cm}^{-2} \mathrm{~s}^{-1}$, dengan nilai banding kadmium rata-rata 4,172. Sistem PGNAA dengan sumber neutron isotopik PuBe yang ada di fasilitas reaktor Kartini dapat mengaktivasi sampel semen dengan cukup baik. Hasil uji coba menggunakan sampel semen terdeteksi 4 puncak energi gamma yang diindikasi sebagai unsur mayor pada sampel semen yaitu unsur ${ }^{59} \mathrm{Fe}$ dan ${ }^{28} \mathrm{Al}$ dan juga unsur-unsur minor dari sampel semen yaitu ${ }^{63} \mathrm{Zn},{ }^{25} \mathrm{Na}$, dan ${ }^{56} \mathrm{Mn}$. Dilihat dari waktu paruhnya, dapat diketahui bahwa beberapa unsur yang berasal dari aktivasi prompt gamma (gamma serentak) adalah ${ }^{28} \mathrm{Al}$ dan ${ }^{25} \mathrm{Na}$. Hal ini dikarenakan kedua unsur tersebut memiliki waktu paruh yang sangat pendek sehingga tidak mungkin dideteksi dengan metode DGNAA.

\section{UCAPAN TERIMA KASIH}

Penulis ingin mengucapkan terima kasih sedalam-dalamnya kepada berbagai pihak yaitu Departemen Teknik Nuklir dan Teknik Fisika, Fakultas Teknik, Universitas Gadjah Mada dan PSTA-BATAN Yogyakarta serta para pembimbing peneliti atas dukungan yang diberikan selama penelitian berlangsung.

\section{DAFTAR PUSTAKA}

[1] S. Niese, "George De Hevesy (1885-1966) Founder of Radioanalytical Chemistry". Czech. J. Phys. vol 56, 2006.

[2] Manuel L. at al. "Applied Radiation and Isotopes", vol 69, no 12, pp 1928-1931, 2011. 
[3] M.R. A Abdi, K.H. Rezaee, Shahayan P and Farazneh A, Middle-East Journal of Scientific Research, vol 11, no 5, pp 648-651, 2012.

[4] INTERNATIONAL ATOMIC ENERGY AGENCY, "Database of Prompt Gamma Rays From Slow Neutron Capture For Elemental Analysis", STI/PUB/1263, Vienna, 2007.

[5] Akhtar A N, et al. Journal of Nuclear Science and Technology, vol 46, no 7, pp 737-743, 2012.

[6] Alexandre S L, Daniel C, Zsoltrevay 2011 Feasibility of the Prompt-Gamma Neutron Activation Analysis Facility at Triga IPR-R1 Reactor in Brazil, International conference on research reactor safe management and effective utilization, Proc. IAEA-CN-188-A19, Rabat Morocco 14-18 Nov, pp 1-8, 2011.

[7] Syarip. "Eksperimen pembuatan sistem penganalisis unsur dengan metode gamma serentak menggunakan sumber neutron PuBe". Ganendra Majalah Iptek Nuklir, vol 5, no. 1, pp 23-30, 2002.

[8] Edi Triyono BS, Syarip S, "Analisis awal rancangan sistem PGNAA menggunakan sumber neutron dari beamport reaktor Kartini", Jurnal Sains dan Teknollogi Nuklir Indonesia, vol 18, no 1, pp 1-14, 2017.

[9] Syarip and Z Abidin, "Set-up of Prompt Gamma Neutron Activation Analysis System at Kartini Reactor", J. Phys.: Conf. Ser. vol 1080, 012030, 2018.

[10] Tegas S, Syarip S, "Karakteristik berkas pada beam port tembus dan singgung reaktor Kartini", Ganendra Majalah Iptek Nuklir, vol 17, no 2, pp 83-90, 2014.

[11] T. Sutondo, S Syarip. "Shielding Design for the PGNAA Experimental Facility at Kartini Reactor". J. Atom Indonesia, vol 44, no 3, pp 131-135, 2018.

[12] Tegas Sutondo "Beam Modeling for PGNAA Experimental Facility at Kartini Reactor", Ganendra Majalah Iptek Nuklir, vol 18, no 2, pp 107-113, 2015.

[13] Peraturan Kepala Badan Pengawas Tenaga Nuklir Nomor 4 Tahun 2013. Tentang Proteksi dan Keselamatan Radiasi dalam Pemanfaatan Tenaga Nuklir, 2013

[14] Fantidis J G, Nicolaou G E, Potolias C, Vordos N, Bandekas D V, J Radioanal Nucl Chem, vol 290, pp 289-295, 2011.

[15] SNI 15-2049-2004. "Semen Portland", Badan Standarisasi Nasional, 2004.

[16] Suci Wulandari I. P., Nurlaela Rauf, dan Eko Juarlin. "Pembuatan dan Pengujian Kualitas Semen Portland yang Diperkaya Silikat Abu Ampas Tebu", Jurnal Fisika FMIPA Universitas Hasanuddin. Makassar, 2015.

[17] Tarek Q. Q, Tawfeq Al-Etaiwi, Mohammed Al-Khasheb, "Analysis and Developments of PGNAA Installation at Al-Rashadiya Lafarge Cement Plant in Jordan", Proc. of the 2011 Intl. Conf. on Industrial Engineering and Operations Management, Kuala Lumpur, Malaysia, January 22 - 24, pp 1219-1224, 2011

[18] Darrell L "PGNAA improves process and quality control in cement production", Accelerating Science, 2014.

[19] Peraturan Kepala Badan Pengawas Tenaga Nuklir Nomor 15 Tahun 2015 Tentang Keselamatan Radiasi Dalam Produksi Pesawat Sinar-X Radiologi Diagnostik dan Intervensional

[20] Peraturan Kepala Badan Pengawas Tenaga Nuklir Nomor 3 Tahun 2013 tentang Keselamatan Radiasi dalam Penggunaan Radioterapi.

[21] International Atomic Energy Agency (IAEA), Radiation Protection and Safety of Radiation Sources: International Basic Safety Standards. Interim Edition. General Safety Requirements Part 3. No. GSR Part 3. IAEA, Vienna 2014. 